\title{
SPORADIC MEDULLARY THYROID CARCINOMA: CLINICAL DATA FROM A UNIVERSITY HOSPITAL
}

\author{
Joya Emilie M. Correia-Deur, ${ }^{\mathrm{I}}$ Rodrigo A. Toledo, ${ }^{\mathrm{I}}$ Alice T. Imazawa, ${ }^{\mathrm{I}}$ Delmar M. \\ Lourenço Jr., ${ }^{I}$ Marilza C. L. Ezabella, ${ }^{I}$ Marcos R. Tavares, ${ }^{I I}$ Sergio P. A. Toledo ${ }^{\mathrm{I}}$
}

doi: $10.1590 / \mathrm{S} 1807-59322009000500002$

Correia-Deur JEM, Toledo RA, Imazawa AT, Lourenço Jr. DM, Ezabella MCL, Tavares MR et al. Sporadic medullary thyroid carcinoma: clinical data from a University Hospital. Clinics. 64(5):379-86.

INTRODUCTION: Medullary thyroid carcinoma may occur in a sporadic (s-medullary thyroid carcinoma, 75\%) or in a multiple endocrine neoplasia type 2 form (MEN2, 25\%). These clinical forms differ in many ways, as s-medullary thyroid carcinoma cases are $R E T$-negative in the germline and are typically diagnosed later than medullary thyroid carcinoma in MEN2 patients. In this study, a set of cases with s-medullary thyroid carcinoma are documented and explored.

PURPOSE: To document the phenotypes observed in s-medullary thyroid carcinoma cases from a university group and to attempt to improve earlier diagnosis of s-medullary thyroid carcinoma. Some procedures for diagnostics are also recommended.

METHOD: Patients $(n=26)$ with apparent s-medullary thyroid carcinoma were studied. Their clinical data were reviewed and peripheral blood was collected and screened for RET germline mutations.

RESULTS: The average age at diagnosis was 43.9 years $( \pm 10.82 \mathrm{SD})$ and did not differ between males and females. Calcitonin levels were increased in all cases. Three patients presented values that were 100-fold greater than the normal upper limit. Most $(61.54 \%)$ had values that were 20 -fold below this limit. Carcinoembryonic antigen levels were high in $70.6 \%$ of cases. There was no significant association between age at diagnosis, basal calcitonin levels or time of disease onset with thyroid tumor size (0.6-15 $\mathrm{cm})$. Routine thyroid cytology yielded disappointing diagnostic accuracy (46.7\%) in this set of cases. After total thyroidectomy associated with extensive cervical lymph node resection, calcitonin values remained lower than $5 \mathrm{pg} / \mathrm{mL}$ for at least 12 months in eight of the cases (30.8\%). Immunocyto- and histochemistry for calcitonin were positive in all analyzed cases. None of the 26 cases presented germline mutations in the classical hotspots of the RET proto-oncogene.

CONCLUSION: Our cases were identified late. The basal calcitonin measurements and immunostaining for calcitonin were highly useful for diagnosing s-medullary thyroid carcinoma. The rate of complete patient recovery was low, and none of the parameters analyzed were useful predictors of the thyroid tumor size. Our findings support previous recommendations for routine serum calcitonin evaluation and immunostaining analysis involving single thyroid nodules.

KEYWORDS: Calcitonin; Thyroid nodules; Thyroid biopsy; RET analysis.

\section{INTRODUCTION}

Medullary thyroid carcinoma (MTC) is a rare neuroendocrine tumor derived from the parafollicular C-cells that secrete calcitonin. It represents $4 \%-5 \%$ of all thyroid

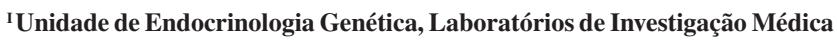
(LIM-25), Hospital das Clínicas da Faculdade de Medicina da Universidade de São Paulo São Paulo - São Paulo/SP, Brazil.

II Departamento de Cirurgia de Cabeça e Pescoço, Faculdade de Medicina da Universidade de São Paulo - São Paulo/SP, Brazil.

Email: toldo@usp.br

Tel.: 55113061.7252

Received for publication on October 23, 2008

Accepted for publication on January 28, 2009 cancers $^{1,2}$ and is prevalent in $0.57 \%-1.37 \%$ of thyroid nodular diseases. ${ }^{3-7}$ Most MTCs occur in a sporadic form (s-MTC), whereas $25 \%-30 \%$ are inherited as the predominant component of multiple endocrine neoplasia type 2 (MEN2) syndromes MEN2A, MEN2B and familial MTC. ${ }^{8}$ In MEN2, MTC is caused by activating germline mutations in the RET proto-oncogene, which is located at chromosome 10 (10q11.2), and encodes a receptor protein tyrosine kinase known as the RET receptor. ${ }^{9}$ All cases with MTC, with or without a clear family history of the disease, should be submitted for RET mutation analysis. Approximately $7 \%$ of the cases with apparent s-MTC harbor a germline mutation, and are therefore indeed familial cases. Furthermore, many 
s-MTC cases may present with thyroid somatic mutations, mostly in RET codon $918 .{ }^{10-11}$

The sporadic form of MTC is defined by the absence of a familial history for MTC as well as a lack of RET germline mutations and other MEN2A-related tumors. Patients with s-MTC are usually diagnosed late during physical examination by the identification of a solitary thyroid nodule, which is typically observed in patients in their 40's and 50's and detected by either high serum levels of calcitonin, cytology from fine needle thyroid biopsy (preferentially with immunostaining for calcitonin) or both. It presents with a slow growth and spreads quickly to regional cervical lymph nodes. At the time of diagnosis, up to $70 \%$ of cases may present with local cervical metastasis. A distant metastasis may occur mainly in the liver, lung, bone and brain. ${ }^{12}$ The only effective treatment for MTC is surgery, as it is usually resistant to conventional chemo- or radiotherapy. ${ }^{13-17} \mathrm{New}$ therapies for MTC, which are being tested in clinical trials, are mostly novel targeting chemotherapies ${ }^{18}$. The outcome of s-MTC depends on the extent of the disease, nature of tumor biology and efficacy of surgical treatment. In general, a 10year survival rate of $60 \%-70 \%$ is observed. ${ }^{19}$

In the sporadic form, MTC differs from the MTC in MEN2 in many ways: 1) it has a later disease onset and is associated with later diagnoses, 2) it is usually less aggressive, 3) the thyroid nodule is unilateral and unicentric, 4) there exists no other associated MEN2-neoplasia, 5) it lacks a germline mutation in the RET proto-oncogene, and 6) family members are not affected by the disease. Although RET mutation analysis of at-risk family members currently allows for early diagnosis in MEN2, the positive identification of s-MTC is usually performed late, which leads to a low surgical and biochemical "cure" (i.e., calcitonin $<5 \mathrm{pg} / \mathrm{mL}$ for at least 12 months).

Calcitonin is a highly sensitive biochemical marker for MTC; however, it has a lower specificity. Thus, hypercalcitoninemia may also be related to the use of drugs such as omeprazole. It may also be related to diseases such as autoimmune thyroiditis or other thyroid tumors, such as papillary thyroid carcinoma (PTC) and follicular thyroid tumor (FTC), renal insufficiency, neuroendocrine tumors and C-cell hyperplasia. ${ }^{20-23}$

The early diagnosis of s-MTC remains a challenge. Most investigators agree that routine measurements of serum calcitonin in all cases with thyroid nodules may substantially increase the rates of early diagnosis and cure for s-MTC. ${ }^{4-7,23-25}$ Furthermore, increased levels of calcitonin are often the only indicator of MTC at early stages of the disease. ${ }^{26}$ This procedure, however, is not advocated worldwide. ${ }^{27}$

We therefore decided to retrospectively investigate cases with MTC but without associated familial history as identified by our facility over the past 26 years. A number of these patients were primarily followed by other institutions and then referred to our unit for treatment. Clinical data, calcitonin values, thyroid biopsies, imaging studies and pathological findings were recorded, reviewed and statistically analyzed.

\section{MATERIALS AND METHODS}

Subjects: We reviewed the clinical and familial histories of 26 patients with apparent s-MTC but without associated familial history. All patients were followed by our group at the Genetic Endocrinology Unit, Department of Endocrinology, at the Hospital das Clínicas (University of São Paulo School of Medicine). The time of MTC incidence was estimated from the interval between the appearance of the thyroid nodule and admission for surgery. Over the past few years, serum calcitonin values have been measured using three different assays: 1) a radioimmunoassay commercial kit (RIA) (Diagnostics Product CorporationDPC, USA) in which the upper normal value is $50 \mathrm{pg} / \mathrm{mL}$ 2) an immunoradiometric assay (IRMA) (Cisbio Bioassays International-CISBIO, France) with an upper normal value of $10 \mathrm{pg} / \mathrm{mL}$ and 3) since 2002, a commercial automated chemiluminescent immunoassay kit (Diagnostics Product Corporation- DPC IMMULITE ${ }^{\circledR}$, USA) with normal values for men of up to $8.4 \mathrm{pg} / \mathrm{mL}$ and for women of up to 5.0 $\mathrm{pg} / \mathrm{mL}$. We performed routine biochemical exams using typical automated methods. Thyroid-stimulating hormone (TSH) was measured by immunofluorometric assay (IFMA) (Wallac, Auto-Delphia, Perkin Elmer, Turku, Finland), with normal values ranging from 0.3 to $4.5 \mu \mathrm{U} / \mathrm{mL}$. Free-T4 was measured by fluoroimmunoassay (FIA) (Wallac, AutoDelphia, Perkin Elmer, Turku, Finland), with normal values ranging from 0.7 to $1.5 \mathrm{ng} / \mathrm{dL}$. Finally, CEA was measured between 1982 and 2000 by enzyme immunoassay (EIA) and between 2001 and 2006 by chemiluminescence immunoassay (Diagnostics Product Corporation- DPC IMMULITE ${ }^{\circledR}$, USA), with normal values for non-smokers of up to 5.0 $\mathrm{ng} / \mathrm{mL}$ and for smokers of up to $10.0 \mathrm{ng} / \mathrm{mL}$. Thyroid ultrasounds and fine needle biopsies were performed using routine methods. Immunocyto- and immunohistochemical reactions for calcitonin were performed by our institution's pathology department as previously reported. ${ }^{28}$ The sizes of the thyroid nodules were estimated in centimeters by ultrasound and/or by pathological measurements.

DNA extraction: Peripheral blood was collected from all patients and screened for RET mutations as previously reported. ${ }^{29-32}$ All patients signed an informed consent form before their blood was collected. 
Statistical analysis: Descriptive analyses were given for all variables. Medians for calcitonin and CEA were calculated, as these values were not normally distributed. Statistical assessments included the Pearson correlation coefficient, the Student's t-test and the Mann-Whitney test. A $p$ value of less than 0.05 was regarded as statistically significant. All analyses were performed using the STATA 8.0 statistical software.

This project was submitted and approved by the Ethical Committee of Hospital das Clínicas da Faculdade de Medicina da Universidade de São Paulo (CAPPesq) and the National Council of Ethics (CONEP).

\section{RESULTS}

\section{Clinical data}

Age

A total of 26 patients followed from 1982-2006 with the diagnosis of apparent s-MTC were enrolled in this study (Table 1). The average age at diagnosis was $43.9 \pm 10.82$ years, and no gender differences were observed (males, $47.08 \pm 11.62$; females, $42.04 \pm 10.18 ; p=0.25$ ) (Table 1).

\section{Thyroid nodules}

The vast majority of patients $(92.3 \%)$ had a clinical history of a single thyroid nodules and most (65.4\%) stated that they had felt something unusual 1-5 years before diagnosis. Two patients did not have a history and did not exhibit palpable nodules at the time of diagnosis. All levels of TSH and free-T4 were within normal limits.

\section{Cervical metastasis}

Cervical ultrasound data from 18 cases showed enlarged lymph nodes compatible with local metastases in nine cases (50\%). Pathological data were recovered from 26 cases, and MTC cervical lymph nodes metastases were documented in 10 cases $(38.5 \%)$.

Table 1 - Clinical and biochemical data for the 26 patients

\begin{tabular}{|c|c|c|c|c|c|c|c|c|c|}
\hline Case & Gender & $\begin{array}{l}\text { History of Thyroid } \\
\text { nodule } \\
(\mathrm{yr})\end{array}$ & $\begin{array}{c}\text { Age at } \\
\text { diagnosis } \\
(y r)\end{array}$ & $\begin{array}{c}\text { TSH } \\
(\mu \mathrm{U} / \mathrm{mL})\end{array}$ & $\begin{array}{l}\text { free T4 } \\
(\mathrm{ng} / \mathrm{dL})\end{array}$ & $\begin{array}{c}\text { CEA } \\
(\mathrm{ng} / \mathrm{mL})\end{array}$ & $\begin{array}{c}\text { Calcitonin } \\
(\mathrm{pg} / \mathrm{mL})\end{array}$ & $\begin{array}{l}\text { Calcitonin } \\
\text { Method** }\end{array}$ & $\begin{array}{c}\text { Fold } \\
\text { Increase }\end{array}$ \\
\hline 1 & M & 0.7 & 44 & 3.4 & 1.0 & 139.5 & 220.0 & B & 7.3 \\
\hline 2 & M & 1.0 & 57 & & & 16.3 & 937.3 & B & 18.7 \\
\hline 3 & M & 1.0 & 33 & & & 0.3 & 40.0 & $\mathrm{C}$ & 8.7 \\
\hline 4 & M & 4.0 & 30 & 1.1 & 1.0 & 100.0 & 1063.3 & B & 21.3 \\
\hline 5 & $\mathrm{~F}$ & 1.0 & 43 & 2.8 & 1.2 & 40.0 & 422.5 & A & 8.4 \\
\hline 6 & $\mathrm{~F}$ & N.H.* & 47 & 1.0 & 1.0 & 7.0 & 625.0 & B & 12.5 \\
\hline 7 & $\mathrm{~F}$ & 5.0 & 25 & & & 1.8 & 19.0 & $\mathrm{C}$ & 4.1 \\
\hline 8 & $\mathrm{~F}$ & 4.0 & 40 & 0.7 & 1.0 & 6.4 & 56.5 & A & 1.1 \\
\hline 9 & $\mathrm{~F}$ & 3.0 & 38 & 1.0 & 1.1 & 24.7 & 22.4 & B & 0.4 \\
\hline 10 & M & 0.8 & 57 & 2.9 & 1.0 & - & 4170.0 & $\mathrm{C}$ & 362.6 \\
\hline 11 & $\mathrm{~F}$ & 1.0 & 17 & 2.4 & 1.2 & 9.8 & 990.0 & B & 19.8 \\
\hline 12 & $\mathrm{M}$ & 20.0 & 61 & 3.2 & 1.2 & - & 1500.0 & A & 25.0 \\
\hline 13 & $\mathrm{~F}$ & 1.0 & 53 & & & 10.0 & 350.0 & B & 70.0 \\
\hline 14 & $\mathrm{~F}$ & 4.0 & 43 & 1.6 & 1.1 & 2.7 & 873.0 & B & 17.5 \\
\hline 15 & M & 0.8 & 42 & 1.9 & 1.0 & 45.0 & 335.0 & B & 18.6 \\
\hline 16 & $\mathrm{~F}$ & 8.0 & 46 & & & 59.9 & 630.0 & $\mathrm{C}$ & 12.6 \\
\hline 17 & $\mathrm{~F}$ & 0.7 & 40 & 2.2 & 1.2 & 32.8 & 1630.0 & $\mathrm{C}$ & 326.0 \\
\hline 18 & $\mathrm{~F}$ & 4.0 & 50 & 2.5 & 1.3 & 87.7 & 3135.5 & B & 627.1 \\
\hline 19 & $\mathrm{~F}$ & 1.0 & 42 & 1.5 & 1.2 & 1.5 & 107.3 & A & 2.1 \\
\hline 20 & M & 1.0 & 41 & 1.4 & 1.3 & 5.5 & 50.0 & B & 1.7 \\
\hline 21 & $\mathrm{M}$ & 0.5 & 42 & 3.3 & 1.0 & 1.5 & 71.0 & A & 2.7 \\
\hline 22 & $\mathrm{~F}$ & 1.0 & 61 & 1.7 & 1.1 & 15.6 & 1435.6 & B & 47.9 \\
\hline 23 & $\mathrm{~F}$ & 5.0 & 40 & 1.6 & 1.0 & 36.8 & 2411.0 & B & 48.2 \\
\hline 24 & M & N.H.* & 63 & 0.7 & 1.0 & 100.0 & 1401.0 & A & 46.7 \\
\hline 25 & $\mathrm{~F}$ & 2.0 & 47 & 1.2 & 1.1 & 46.6 & 326.0 & $\mathrm{C}$ & 70.9 \\
\hline 26 & $\mathrm{~F}$ & 1.0 & 41 & 3.1 & 1.2 & 2.0 & 97.0 & $\mathrm{C}$ & 19.4 \\
\hline
\end{tabular}

* N.H. No history at the time of diagnosis. ** A=radioimmunoassay (RIA), $\mathrm{B}=$ immunoradiometric assay (IRMA), $\mathrm{C}=$ chemiluminescent immunoassay. ${ }^{* * *}$ Calcitonin value fold increase over normal according to the method used. 


\section{Calcitonin and CEA values}

Basal calcitonin levels were high at the time of diagnosis and ranged from 19.0 to $4,170.0 \mathrm{pg} / \mathrm{mL}$. Since part of this wide range could be explained by the fact that the three methods used had different normal values for calcitonin, we calculated how many times it was above the upper normal limit for each patient. Three patients presented with values that were 100-fold greater than the normal upper limit. Most of the patients $(61.54 \%)$ exhibited values that were 20 -fold below this level. There were no differences in calcitonin values between genders $(p=0.99)$. As listed in Table 1 , the variability across subjects remained, and it was not possible to identify a potential factor that would explain this phenomenon using time of disease, age at diagnosis, size of the tumor, or presence of metastases at the time of diagnosis as prognostic factors. Levels of CEA were abnormally high in 17 (70.8\%) of the 24 cases (median, $15.9 \mathrm{ng} / \mathrm{mL}$; SD, 38.6) (Table 1).

\section{Thyroid tumor size}

The thyroid tumor size, estimated by either ultrasound and/or pathological data in 26 cases, varied from 0.6 to $15 \mathrm{~cm}$ (Table 2). To estimate the possible correlation of the tumor size with calcitonin levels, duration of the disease and the outcome (cure/no cure), we separated the tumor size into smaller than $1 \mathrm{~cm}$ and larger than $1 \mathrm{~cm}$ diameter categories. We found no differences between the two groups. We then created another category, separating tumor size into three groups - up to $1 \mathrm{~cm}$, between 1.1 and $1.4 \mathrm{~cm}$, and larger than $1.5 \mathrm{~cm}$. Again, no significant difference was observed $(\mathrm{p}>0.05)$.

\section{Association}

The Pearson's correlation test was employed to test for linear associations between two variables. A Student's t-test was used to evaluate the differences in means between the two groups. There was no significant difference in calcitonin or CEA levels among the categories of thyroid nodule size in our patients $(p>0.05)$. Furthermore, there was no significant correlation between the time since diagnosis and the age at diagnosis with serum calcitonin levels, CEA or thyroid tumor sizes. Although males with MTC tended to be older than affected females at diagnosis, no significant differences were observed $(\mathrm{p}=0.25)$. Basal calcitonin levels presented a wide range of variation in these cases, but this variation did not differ between males and females $(p=0.99)$. Levels of CEA were higher in cases with more extensive metastases, but these differences were not significant $(\mathrm{p}=0.12)$.

\section{Pathologic data}

\section{Cytological data}

Cytological analyses performed on thyroid samples obtained through fine needle biopsies of the thyroid nodules were recovered for $15(57.7 \%)$ patients and were consistent with MTC in seven of those cases (46.7\%). Papillary thyroid carcinoma (PTC) was found in two cases, mixed PTC and MTC in one case, follicular thyroid tumor (FTC) in two cases and a Riedel tumor in one. Thus, in eight cases, the cytological finding per se was inconsistent with an MTC diagnosis. Using routine analysis techniques, immunocytochemical staining was performed in 3 of the 15 cytologically studied cases $(20.0 \%)$. All reactions were markedly positive for calcitonin (Table 2).

\section{Histopathological findings}

Data from pathological analyses were recovered in all cases. The diagnoses were compatible with MTC in all patients with $100 \%$ accuracy. One case presented with a mixed medullary/papillary thyroid tumor. Immunohistochemical analysis was performed in 11 cases $(42.3 \%)$. All reactions were strongly positive for calcitonin, which was compatible with MTC (Table 2).

\section{Post-surgical follow-up}

Twelve patients $(46.2 \%)$ were thyroidectomized in other institutions prior to follow up by our group. A total thyroidectomy and central and bilateral neck dissection (levels II to VII) was performed in the other 14 s-MTC patients using a previously described surgical approach. ${ }^{33}$ There was no difference in calcitonin levels, time of disease or size of thyroid nodules between these two groups. Eight patients $(30.8 \%)$ presented with post-surgical calcitonin levels lower than $5 \mathrm{pg} / \mathrm{mL}$ for at least 12 months after surgery. These cases were initially classified as biochemically relapsed. One patient was considered inoperable and died soon after diagnosis (case 10) (3.9\%), and 17 cases $(65.4 \%)$ were not biochemically cured. No differences were observed in tumor size, time of disease, age at diagnosis, or calcitonin levels between the group that was classified as biochemically relapsed and the group that was not.

\section{$R E T$ mutation analysis}

No RET germline mutations were identified in any of the 26 cases, confirming the presence of the sporadic form of MTC in all patients.

\section{DISCUSSION}

In modern molecular medicine, genetic screening is an increasingly useful tool ${ }^{35}$ that is currently applied to inherited tumor syndromes such as multiple endocrine neoplasia types $1^{36}$ and $2 .{ }^{31}$ 
Table 2 - Cytological and pathological data from the 26 patients

\begin{tabular}{|c|c|c|c|c|c|c|}
\hline \multirow[t]{2}{*}{ Case } & \multirow[t]{2}{*}{ Nodule size $(\mathrm{cm})$} & \multicolumn{2}{|c|}{ Fine needle biopsy } & \multicolumn{2}{|c|}{ Pathological data } & \multirow[t]{2}{*}{ Cure } \\
\hline & & Results $^{1}$ & $\mathrm{ICC}^{2}$ & Results $^{1}$ & $\mathrm{IHC}^{2}$ & \\
\hline 1 & 6.0 & $\mathrm{PTC} / \mathrm{MTC}$ & - & MTC & - & yes \\
\hline 2 & 1.0 & - & - & MTC & positive & no \\
\hline 3 & 2.5 & - & - & MTC & positive & yes \\
\hline 4 & 1.0 & MTC & positive & MTC & - & no \\
\hline 5 & 8.0 & PTC & positive & PTC/MTC & - & no \\
\hline 6 & 1.0 & negative & - & MTC & - & no \\
\hline 7 & 9.0 & PTC & - & MTC & positive & yes \\
\hline 8 & 2.0 & - & - & MTC & positive & yes \\
\hline 9 & 3.0 & MTC & positive & MTC & positive & yes \\
\hline 10 & 15.0 & MTC & - & MTC & - & death \\
\hline 11 & 2.1 & FTC & - & MTC & positive & no \\
\hline 12 & 12.0 & - & - & MTC & - & no \\
\hline 13 & 1.3 & - & - & MTC & - & no \\
\hline 14 & 6.0 & neoplasia & - & MTC & - & no \\
\hline 15 & 0.6 & Riedel & - & MTC & - & no \\
\hline 16 & 4.3 & - & - & MTC & positive & no \\
\hline 17 & 4.8 & - & - & MTC & - & yes \\
\hline 18 & 3.0 & MTC & - & MTC & positive & no \\
\hline 19 & 3.0 & - & - & MTC & - & no \\
\hline 20 & 4.2 & - & - & MTC & positive & no \\
\hline 21 & 2.0 & - & - & MTC & positive & no \\
\hline 22 & 4.0 & MTC & - & MTC & - & no \\
\hline 23 & 1.3 & MTC & - & MTC & positive & no \\
\hline 24 & 1.0 & - & - & MTC & - & no \\
\hline 25 & 2.5 & MTC & - & MTC & - & yes \\
\hline 26 & 0.8 & neoplasia & - & MTC & - & yes \\
\hline
\end{tabular}

${ }^{1} \mathrm{PTC}=$ papillary thyroid carcinoma; MTC $=$ medullary thyroid carcinoma FTC = follicular thyroid carcinoma $;{ }^{2} \mathrm{ICC}=$ immunocytochemistry; ${ }^{3} \mathrm{IHC}=$ immunohistochemistry

A routine search for RET germline mutations in all cases that presented with MTC and/or pheochromocytoma and in at-risk family members from MEN2 genealogies is recommended worldwide and is frequently performed in Brazil. ${ }^{30-32}$ This procedure has been critical in the early detection of RET mutation carriers and has prompted the recommendation of prophylactic total thyroidectomy in the case of younger RET-positive carriers. ${ }^{10}$ This may dramatically modify the outcome of MTC in MEN2 and may lead to a definitive surgical and biochemical cure of this disease in younger, asymptomatic RET-positive carriers. ${ }^{9,10,12}$

The early recognition of s-MTC cases, however, remains a challenge. The diagnosis of s-MTC is usually late and is performed only when a thyroid nodule is already detectable either by ultrasound (frequently with diameters from 0.2 to $0.9 \mathrm{~cm}$ ) or by palpation $(>1.0 \mathrm{~cm})$. At this latter stage, cervical metastases are often already present (50\%-70\%). Furthermore, research has shown that MTC tumors with a diameter of $1.0 \mathrm{~cm}$ may have been growing for 3-4 years. ${ }^{3}$ At diagnosis, basal calcitonin levels are high in almost all s-MTC cases, a finding which is certainly expressed by our data. Cytological data obtained from thyroid biopsies, however, may not be associated with good rates of diagnostic accuracy, as observed in our study. Often on account of late diagnoses, persistent biochemical cure after the first thyroid surgery or reoperation is only achieved in $\sim 30 \%$ of the cases,${ }^{38}$ similar to the apparent rate of biochemical cure (30.8\%) observed in the present cases.

In attempting to improve the early diagnosis of s-MTC, several authors have recommended routine serum calcitonin measurements in all cases with thyroid 
nodule disease..$^{5-7,23-25,34}$ This procedure has primarily been suggested by European investigators since 1994 and has been supported by several other studies. ${ }^{5-7}$ In Brazil, it has been recommended that a systematic approach of single solid thyroid nodule be employed by means of routine evaluation of basal calcitonin values. ${ }^{34}$ Others have also recommended this procedure. ${ }^{37} \mathrm{Up}$ to $1.4 \%$ of previously unsuspected MTC cases have been reported in unselected sequential cases presenting with thyroid nodules. ${ }^{23}$ Furthermore, the cost benefits of routine calcitonin measurements and of therapeutic procedures have recently been evaluated. In cases with local and advanced metastases, the data favored the procedure. ${ }^{23}$ It is worth noting that MTC is usually resistant to conventional chemo- and radiotherapy, which motivates the need for the early detection of this condition. This management for thyroid nodules, however, has not been recommended worldwide. ${ }^{27}$

We documented consistently high basal levels of calcitonin in all $26 \mathrm{~s}-\mathrm{MTC}$ patients, confirming that this serum marker is very sensitive for biochemical diagnosis. A cohort study ${ }^{24}$ showed that MTC was confirmed in almost all patients with thyroid nodules associated with calcitonin values higher than $100 \mathrm{pg} / \mathrm{ml}$. Thus, this cut-off point for basal calcitonin levels has been frequently used to discriminate between cases with and without MTC. ${ }^{26}$

In our sample, age at diagnosis, calcitonin levels and time of disease were not associated with the thyroid tumor size, consistent with previous suggestions. ${ }^{13}$ These findings indicate that these parameters may not be accurate predictors of MTC outcomes in our specific sample.

In our study, post-surgical follow-up was performed in 24 MTC cases (92.3\%). Persistently low levels of calcitonin (< $5 \mathrm{pg} / \mathrm{mL}$ ) after thyroid surgery were present in eight patients $(30.8 \%)$. This relatively low rate of surgical success suggests a late diagnosis of MTC in our cases. Similar apparent biochemical cure rates $(33 \%)$ have been reported by others. ${ }^{13}$ Our institution currently recommends that patients diagnosed late with s-MTC should undergo a total thyroidectomy, central and bilateral neck dissection (levels II to VII) as well as a thymectomy and resection of the thymic lymph nodes. ${ }^{33}$ This latter procedure appears to increase the surgical success rate in MTC (Tavares, MR - unpublished data).

In our cases, pathologic data were compatible with MTC in all 26 patients. Immunohistochemical analysis was performed in nearly half of the cases and the new data reinforced the MTC diagnosis on every occasion. Conversely, when applied to the present cases, thyroid cytology exhibited a low accuracy (46.7\%). Given the small number of biopsies that were recovered $(57.7 \%)$, the lower accuracy rate may be due to information bias. One must also consider the fact that only $20 \%$ of the fine needle biopsies were complemented by immunocytochemical reactions (ICC). In our sample, immunocytochemical staining was indicative of MTC in all analyzed cases, including one thyroid cytology that was diagnosed as PTC. Immunocytochemical analysis may therefore increase the accuracy of the fine needle biopsy procedure. The diagnosis of MTC, which is essential for both the surgical approach to the primary tumor and for related patient management, should rely not only on thyroid cytology but should also take into account immunocytochemical reactions. It is also worth noting that thyroid cytology may occasionally fail to present with a sufficient number of cells to permit an adequate cytological examination.

These findings suggest that immunocyto- and/or immunohistochemical reactions to calcitonin should be routinely performed in all cases of suspected MTC to improve the early recognition of this neoplasia.

Finally, the systematic mutation analysis of the six RET proto-oncogene hot-spot exons applied to our 26 patients allowed us to confirm the presence of the sporadic form of MTC (Toledo RA et al., unpublished data).

Data from this specific set of s-MTC cases have given further support to the recommendation that serum calcitonin measurements should be performed in all patients who present with thyroid nodules in an attempt to diagnose s-MTC at earlier stages. It would also be advisable for clinicians to routinely ask for immunocytoand histochemical reactions to calcitonin in all cases where suspected thyroid nodules present in the context of MTC.

\section{ACKNOWLEDGEMENTS}

Rodrigo A. Toledo was supported by a CAPES Grant and Alice T. Imazawa, Delmar M. Lourenço-Jr., and Sergio P.A. Toledo were supported by a Fundação Faculdade de Medicina Grant.

\section{REFERENCES}

1. Marsh DJ, Learoyd DL, Robinson BG. Medullary thyroid carcinoma: recent advances and management update. Thyroid. 1995;5:407-24.
2. Sherman SI, Angelos P, Ball DW, Beenken SW, Byrd D, Clark OH, et al. National Comprehensive Cancer Network. Thyroid carcinoma. J Natl Compr Canc Netw. 2005;3:404-57. 
3. Sizemore GW, Carney JA, Heath H 3rd. Epidemiology of medullary carcinoma of the thyroid gland: a 5-year experience (1971-1976). Surg Clin North Am. 1977;57:633-45.

4. Henry JF, Denizot A, Puccini M, Gramatica L, Kvachenyuk A, ConteDevolx B, et al. Latent subclinical medullary thyroid carcinoma: diagnosis and treatment. World J Surg. 1998;22:752-7.

5. Pacini F, Fontanelli M, Fugazzola L, Elisei R, Romei C, Di Coscio G, et al. Routine measurement of serum calcitonin in nodular thyroid diseases allows the preoperative diagnosis of unsuspected sporadic medullary thyroid carcinoma. J Clin Endocrinol Metab. 1994;78:826-9.

6. Rieu M, Lame MC, Richard A, Lissak B, Sambort B, Vuong-Ngoc P, et al. Prevalence of sporadic medullary thyroid carcinoma: the importance of routine measurement of serum calcitonin in the diagnostic evaluation of thyroid nodules. Clin Endocrinol (Oxf.). 1995;42:453-60.

7. Niccoli P, Wion-Barbot N, Caron P, Henry JF, de Micco C, Saint Andre $\mathrm{JP}$, et al. Interest of routine measurement of serum calcitonin: study in a large series of thyroidectomized patients. J Clin Endocrinol Metab. 1997;82:338-41.

8. Hundahl SA, Fleming ID, Fremgen AM, Menck HR. A National Cancer Data Base report on 53,856 cases of thyroid carcinoma treated in the U.S., 1985-1995 [see commetns]. Cancer. 1998;83:2638-48.

9. Fialkowski EA \& Moley JF. Current Approaches to Medullary Thyroid Carcinoma, Sporadic and Familial. J Surg Oncol. 2006;94:737-47.

10. Brandi ML, Gagel RF, Angeli A, Bilezikian JP, Beck-Peccoz P, Bordi $\mathrm{C}$, et al. CONSENSUS: Guidelines for Diagnosis and Therapy of MEN Type 1 and Type 2. J Clin Endocrinol Metab. 2001;86:5658-71.

11. de Groot JWB, Links TP, Plukker JTM, Lips CJM, Hofstra RMW. RET as a Diagnostic and Therapeutic Target in Sporadic and Hereditary Endocrine Tumors. Endocrine Reviews. 2006;27:535-60.

12. Boikos SA \& Stratakis CA. Molecular mechanisms of medullary thyroid carcinoma: current approaches in diagnosis and treatment. Histol Histopathol. 2008;23:109-16.

13. Gharib H, McConahey WM, Tiegs RD, Bergstralh EJ, Goellner JR, Grant CS, et al. Medullary thyroid carcinoma: clinicopathologic features and long-term follow-up of 65 patients treated during 1946 through 1970. Mayo Clin Proc. 1992;67:934-40.

14. Kebebew E, Ituarte PH, Siperstein AE, Duh QY, Clark OH. Medullary thyroid carcinoma: clinical characteristics, treatment, prognostic factors, and a comparison of staging systems. Cancer. 2000;88:1139-48.

15. Clayman GL \& el-Baradie TS. Medullary thyroid carcinoma and RET. Otolaryngol Clin North Am. 2003;114:91-105.

16. Cohen MS \& Moley JF. Surgical treatment of medullary thyroid carcinoma. J Intern Med. 2003;253:616-26.

17. Gulben K, Berberoglu U, Boyabatli M. Prognostic factors for sporadic medullary thyroid carcinoma. World J Surg. 2006;30:84-90.

18. Yao JC \& Hoff PM. Molecular targeted therapy for neuroendocrine tumors. Hematol Oncol Clin N Am. 2007;21:575-81.

19. Moley JF. Medullary thyroid carcinoma. Curr Treat Options Oncol. 2003;4:339-47

20. Niccoli P, Conte-Devolx B, Lejeune PJ, Carayon P, Henry JF, Roux F, et al. Les hypercalcitoninémies en dehors des cancers médullaires de la thyroïde. Ann Endocrinol (Paris). 1996;57:15-21.
21. Vierhapper H, Raber W, Bieglmayer C, Kaserer K, Weinhäusl A, Niederle B. Routine measurement of plasma calcitonin in nodular thyroid diseases. J Clin Endocrinol Metab. 1997;82:1589-93.

22. Hahm JR, Lee MS, Min YK, Lee MK, Kim KW, Nam SJ, et al. Routine measurement of serum calcitonin is useful for early detection of medullary thyroid carcinoma in patients with nodular thyroid diseases. Thyroid. 2001;11:73-80.

23. Borget I, De Pouvourville G, Schlumberger M. Editorial: Calcitonin Determination in Patients with Nodular Thyroid Disease. J Clin Endocrinol Metab. 2007;92:425-7.

24. Costante G, Meringolo D, Durante C, Bianchi D, Nocera M, Tumino S, et al. Predictive Value of Serum Calcitonin Levels for Preoperative Diagnosis of Medullary Thyroid Carcinoma in a Cohort of 5817 Consecutive Patients with Thyroid Nodules. J Clin Endocrinol Metab. 2007;92:450-5

25. Elisei R, Bottici V, Luchetti F, Di Coscio G, Romei C, Grasso L, et al. Impact of routine measurement of serum calcitonin on the diagnosis and outcome of medullary thyroid cancer: Experience in 10,864 patients with nodular thyroid disorders. J Clin Endocrinol Metab. 2004;89:163-8.

26. Mirallié E, Iacobone M, Sebag F, Henry JF. Results of surgical treatment of sporadic medullary thyroid carcinoma following routine measurement of serum calcitonin. Eur J Surg Oncol. 2004;30:790-5.

27. Cooper DS, Doherty GM, Haugen BR, Kloos RT, Lee SL, Mandel SJ, et al. Management guidelines for patients with thyroid nodules and differentiated thyroid cancer. Thyroid. 2006;16(2):109-42.

28. Hayashida CY, Alves VA, Kanamura CT, Ezabella MC, Abelin NM, Nicolau W, et al. Immunohistochemistry of medullary thyroid carcinoma and C-cell hyperplasia by an affinity-purified anti-human calcitonin antiserum. Cancer. 1993;72:1356-63.

29. Ceccherini I, Hofstra RM, Luo Y, Stulp RP, Barone V, Stelwagen T, et al. DNA polymorphisms and conditions for SSCP analysis of the 20 exons of the RET proto-oncogene. Oncogene. 1994;9:3025-9.

30. Santos MA, Nunes AB, Abelin N, Ezabella MC, Toledo R de A, Lourenço Júnior D, et al. Genetic screening of multiple endocrine neoplasia type 2: experience of the USP Endocrine Genetics Unit. Arq Bras Endocrinol Metab. 2006;50:7-16.

31. Toledo SPA, Santos MA, Toledo RD, Lourenço Junior DM. Impact of RET proto-oncogene analysis on the clinical management of multiple endocrine neoplasia type 2. Clinics. 2006;61:59-70.

32. Santos MA, Quedas EP, Toledo RD, Lourenço-Júnior DM, Toledo SPA Screening of RET gene mutations in multiple endocrine neoplasia type2 using conformation sensitive gel electrophoresis (CSGE). Arq Bras Endocrinol Metabol. 2007;51(9):1468-76.

33. Tavares MR, Michaluart P Jr, Montenegro F, Arap S, Sodré M, Takeda F, et al. Skip Metastases in Medullary Thyroid Carcinoma: A SingleCenter Experience. Surg Today. 2008;38:499-504.

34. Abelin NMA, Gomes S, Ivanoff MT, Ezabella MCL, Hayashida CY, Toledo SPA. Abordagem clínica e laboratorial do bócio uni-nodular sólido: vantagens da determinação da calcitonina sérica por métodos distintos. Arq Bras Endocrinol Metab. 1999;43:104-13.

35. Pieri PC, Missaglia MT, Roque JA, Moreira-Filho CA, Hallak J. Novel CFTR missense mutations in Brazilian patients with congenital absence of vas deferens: counseling issues. Clinics. 2007;62:385-90. 
36. Lourenço-Jr DM, Toledo RA, Coutinho FL, Margarido LC, Siqueira SA, dos Santos MA, et al. The impact of clinical and genetic screenings on the management of the multiple endocrine neoplasia type 1. Clinics. 2007:62:465-76.

37. Hauache OM, Vieira JGH, Maciel RMB. Diagnóstico Laboratorial do Carcinoma Medular de Tiróide: Calcitonina Basal e Testes de Estímulo. Arq Bras Endocrinol Metab. 2003;47:529-33.
38. Tisell L, Hansson G, Jansson S, Salander H. Reoperation in the treatment of asymptomatic metastasizing medullary thyroid carcinoma. Surgery. 1986;99:60-6. 